\title{
Chronic Disorders Nursing
}

National Cancer Institute

\section{Source}

National Cancer Institute. Chronic Disorders Nursing. NCI Thesaurus. Code C19345.

Nursing care and research focused on populations with chronic disorders. 